\title{
What's the difference between work and fun? Explaining the difference between utilitarian and hedonic IT use
}

\author{
Anssi Öörni \\ Åbo Akademi \\ anssi.oorni@abo.fi
}

\author{
Markku Kuula \\ Aalto University \\ markku.kuula@aalto.fi
}

\author{
Mika Pantzar \\ University of Helsinki \\ mika.pantzar@helsinki.fi
}

\begin{abstract}
Information systems theory tells us that the deepest going difference between utilitarian and hedonic information technology use is that different sets of motivational factors direct the two types of use. However, recent advances in social psychology and consumer behavior research suggest that there is an even more profound difference: Only utilitarian IT use depends on the self-control mechanism and the limited resources consumed bu exercise of self-control. This causes the daily and weekly rhythms of utilitarian and hedonic use to be different. Utilitarian information technology use decreases throughout the day and the week while hedonic information technology use does not. In this paper, we test for the first time whether the daily consumption pattern of utilitarian information technology use indeed reflects the hypothesized patterns at the aggregate level. Our data suggests that it does, which means that the self-control mechanism should be integrated in the information systems models that seek to explain information technology use.
\end{abstract}

\section{Introduction}

To discover influences on information technology (IT) use is one of the key tasks of information systems (IS) research. To that end some IS researchers have identified that a single set of motivational factors can't explain all IT use: Different sets of factors, it is suggested, direct utilitarian and hedonic use of IT [1]. In other words, people have different motivations for using IT when technology is used because the use itself is rewarding (hedonic use) or when the technology is used as means in pursuit of some higher level ends. The noted difference between utilitarian and hedonic IT use has seldom been discussed past the aforementioned notion of different sets of motivational factors directing the different types of use (cf. [2]) even though recent advances made in social psychology and consumer behavior research would have enabled such discussion.

Psychologists have shown that repeated cognitive efforts result in worsening performance of subsequent tasks because they deplete resources needed for self-control [3]. Consumer behavior researchers, in turn, have demonstrated that utilitarian and hedonic consumption episodes are different in that hedonic consumption can be sustained much longer than utilitarian consumption: Hedonic consumption episodes vitalize the consumer while utilitarian consumption episodes deplete limited resources of selfcontrol, and performance of subsequent utilitarian consumption episodes becomes increasingly more difficult [4]. The underlying social psychological theory, commonly referred to as the strength model of self-control [5], suggests that self-control is a limited resource that is depleted throughout the day and the week as the individual commits cognitively taxing tasks, completion of which requires self-control. The resource is mainly replenished during rest.

We suggest that the self-control mechanism offers a more in-depth explanation to the differences in utilitarian and hedonic IT use and as such the selfcontrol mechanism should be integrated to models and theories seeking to explain IT use. More precisely, when applied to IT use context, the strength model of self-control suggests that utilitarian and hedonic IT use should follow different trajectories at the aggregate level throughout the day. Utilitarian IT use should follow a declining trajectory over the duration of the day as the self-control reservoirs of consumers get depleted. Use of utilitarian IT should also follow the weekly cycle of peaking on Monday and declining over the weekdays towards the end of the week. Hedonic IT use should not follow the same declining trajectory as utilitarian IT use, for hedonic IT use does not depend the self-control mechanism and the limited resources needed for such control.

The aim of this study is to demonstrate empirically that daily patterns of utilitarian IT use follow the hypothesized cyclic patterns as predicted by the strength model of self-control. We analyze server $\log$ data of consumers' online bank sessions (utilitarian use) of a major retail bank and report the respective daily and weekly consumption patterns of the service. Our findings support the hypothesized cyclic patterns of utilitarian IT use. 


\section{Theory}

Doing something useful is often the antithesis of having fun as exemplified by sayings like "work before pleasure". Use of utilitarian IT is no exception to this rule. Such use is neither rewarding nor an end in and of itself. Rather, utilitarian IT is used as a tool to advance some higher-level goals. Everyday life is filled with tasks we don't fancy doing but do nevertheless because of the perceived benefit of successfully carrying out the task. The shared characteristic of such acts is that they become increasingly difficult over the span of a day even if one's motivation remains constant. It seems that both getting started with even a modestly challenging task and seeing it through depend on one's ability to stay focused on the task, which is largely independent of one's motivation. Further, staying focused on the task seems to consume a resource, which is in limited supply, impairing performance of subsequent cognitive tasks.

Self-control is a cognitive mechanism, which controls allocation of man's mental resources in an automatic fashion [6]. Most crucially, self-control facilitates goal pursuit by inhibiting distractions [7, 8, 9]. Hence, self-control determines, to a large degree, whether people start to pursue a goal at a given time and whether that goal pursuit persists to a successful end. Successful self-control manifests itself in ability to stay focused on one's active goal during the goal pursuit up until the goal has been achieved. Failed selfcontrol, in turn, can have at least two manifestations. One symptom of failed self-control is delayed pursuit of a goal, also known as procrastination [10]. Another symptom of failed self-control is interrupted goalpursuit caused by some distraction causing attention to shift from pursuit of one's present goal to doing something else [11].

Self-control is a mechanism that is more needed during goal pursuits as opposed to goal setting, which is usually equated to motivation [12]. Hence, motivation does not fully determine success in goal pursuit. As the brain is a noisy organ, goals need to be protected from distractions [8]. When self-control is operating to the effect, incoming task-relevant information, produced by one's sense organs, receives preferential treatment, whereas sensations unrelated to the task at hand are largely ignored. As the amount of information produced by the senses greatly exceeds man's conscious information processing capacity, it would be impossible to determine consciously, which pieces of information should be processed to higher levels and which pieces should be discarded. Thus, self-control relies on subconscious, automatic processes to take care of that task. Processes that shape attention do the balancing between focusing on task- relevant information or being distracted by alternative courses of action: "attention biases incoming flow of information and internal representations in the service of effective goal achievement," [9, p. 474].

Self-control is usually characterized as being weakly related or even totally unrelated to one's motivation to commit an act [3]. In other words, the folk psychological term willpower does not do justice to self-control. Even though it is possible to push oneself, at least to a degree, in pursuit of a goal, such conscious efforts have only limited effect on goalachievement. Events of failed goal pursuit reveal that self-control is not dominated by motivation as the individual can become distracted even when she understands that staying focused on goal-pursuit would be in her best interest. Indeed, a salient symptom of failed self-control, procrastination, is defined as "to voluntarily delay an intended course of action despite expecting to be worse off for the delay" [10].

Modern theories of self-control (e.g. $[13,14]$ ) suggest that self-control depends on a limited resource that is depleted throughout the day and the week as people engage in tasks, which are mentally taxing [15]. Self-control is replenished while at rest $[16,17]$. Most interestingly, consumer researchers have recently demonstrated in laboratory settings that self-control mechanism affects differently utilitarian and hedonic tasks [4]. More precisely, they have observed that a somewhat taxing task that is not in itself gratifying (i.e. a utilitarian task) decreases the performance of the subsequent, similar task. No similar effect was observed for tasks that were in themselves rewarding (i.e. hedonic tasks). The researchers suggest that the observed effect was due to the limited self-control resources that were depleted in the utilitarian task. These findings suggest that we should observe different use patterns for utilitarian and hedonic IT: At the aggregate level utilitarian IT use varies with available self-control resources throughout the day: It should peak in the morning, dip in the mid-afternoon, increase slightly in the late afternoon, and then decrease toward the evening. Use of utilitarian IT should also follow weekly cyclic variation in selfcontrol peaking on Monday and decreasing toward the end of the week before being replenished during the weekend. Use of hedonic IT, in turn, is unaffected by variation in resources needed for self-control, for selfcontrol is not needed in such intrinsically rewarding tasks. In fact, engaging in hedonic use may even help restore self-control.

In sum, use of utilitarian IT use is cyclic rather than uniformly distributed as motivational theories imply. It follows a certain daily and weekly patterns, as predicted by recent literature on self-control [3]. Based on that literature, we can make the following 
hypotheses to test for self-control's influence on utilitarian IT use:

H1: On weekdays use of utilitarian IT peaks in the morning and declines toward the evening.

$\mathrm{H} 2$ : Frequency of utilitarian IT use is higher on weekdays compared to the weekend.

H3: Frequency of utilitarian IT use peaks on Monday and declines over the weekdays until Friday.

H4: Frequency of use has a local minimum at midafternoon, when self-control is known to 'dip'.

\section{Methods}

We tested our hypotheses by using a set of longitudinal data obtained from the log files of a major retail bank's online bank. The data was retrieved from the server log files of active user sessions. The online bank data comprise time series of the active user sessions of individual customers of Nordea, one of the largest Finnish retail banks. The data were recorded between December 2010 and November 2011 and include the number of daily active online bank sessions for the whole year and the number of active online sessions by the hour for October 2011 (see Figure 1). Nordea offers different online bank software to its individual customers and business customers. We included in our data only the $\log$ records of individual customers.

\section{Results}

We report next the results of testing our research hypotheses. Our first research hypothesis captures the idea that the number of users using a utilitarian technology does not remain constant throughout the weekday, even if consumers' motivation to use the technology remained constant. Rather, use of the technology varies throughout the day because resources needed for self-control are in limited supply and get depleted:

H1: On weekdays use of utilitarian IT peaks in the morning and declines toward the evening.

We tested the hypothesis using the online bank data set, which contained frequencies of active online sessions by the hour and spanning the period of one month. We first aggregated the hourly use frequencies for each day of the week over the duration of the whole month. We then used Microsoft Excel to fit regression curves to predict the hourly frequencies of active online bank sessions during the active part of the day (from 9AM to 9PM) as we wanted to exclude trivial explanations for observed variation in online bank use, such as people sleeping during the night, from our analysis.

The result obtained by fitting the regression curve to our data supports our first research hypothesis (see Table 1 and Figure 2). Our analysis tells that the number of active online bank sessions peaked in the morning and decreased toward the evening. This pattern is particularly clear for Fridays as online bank use starts to rapidly decline late afternoon, from around 4PM onwards. Frequency distribution of active online bank sessions on Monday was also rather lopsided, mostly because the use reached its all week high on Monday morning around 9AM after which it dwindled toward the evening. Other weekdays displayed similar, if more subdued, pattern of online bank use peaking in the morning and decreasing toward the evening, as predicted by self-control theory.

Self-control theory suggests that the number of users using a utilitarian technology should not remain constant throughout the week either. Rather, as selfcontrol peaks on Monday and dwindles over the weekdays towards the weekend, use frequency of utilitarian technology follows the same pattern. To test for this, we set the following two research hypotheses:

H2: Frequency of utilitarian IT use is higher on weekdays compared to the weekend.

H3: Frequency of utilitarian IT use peaks on Monday and declines over the weekdays until Friday.

We tested hypothesis $\mathrm{H} 2$ using the data set containing daily frequencies for active online bank sessions for the period of the whole year. We tested the hypothesis by comparing the daily averages of active online bank sessions on weekdays against the daily averages of active online bank sessions on weekends using the z-test.

The results support our hypothesis (see Table 2 , Pane 1). The number of active online bank sessions was clearly higher on weekdays compared to the number of active online bank sessions on either Saturday or Sunday. All differences revealed by the pairwise comparisons between weekdays and the days of the weekend were statistically highly significant.

We tested hypothesis H3 using the same data set as used for testing hypothesis $\mathrm{H} 2$ by making pairwise weekday by weekday comparisons on the daily averages of active online bank sessions using the z-statistic. The results of the tests, reported in Table 2 (Pane 2), suggest that the online activity declines rather swiftly early in the week and that the decline tapers off toward Friday. We find statistically significant 
difference in the average number of active online bank sessions for every tested weekday pair except for Thursday and Friday. Looking at the averages in Table 2 , we find substantial decrease in the average number of daily active online bank sessions from the Mondays' high of 329536 to Fridays' low of 238265 active sessions. Overall, the results support our hypothesis.

Finally, self-control theory tells us that available self-control does not usually decrease monotonically during the day. Rather, self-control theory suggests that there should be a mid-afternoon 'dip' in the use of utilitarian IT. We hypothesize that this 'dip' should occur on weekdays rather than on weekends:

H4: Frequency of use has a local minimum at midafternoon, when self-control is known to 'dip'.

We tested hypothesis $\mathrm{H} 4$ using the online bank data collected for the duration of a month. We calculated hourly averages for each weekday over the four-week period. Next, we did pairwise comparisons to compare the mid-afternoon dips in active online bank sessions against morning high and evening high of active online bank sessions. We used z-test for comparisons (see Table 3).

The results of the z-tests lend some if not totally unequivocal support for hypothesis H4. First, the number of active online bank sessions peaked at 10AM each day. It then declined until around 1PM and increased again toward the second peak at around 4PM. We observe a clear mid-afternoon dip on Tuesdays, Wednesdays, and Thursdays. There is no dip on Fridays because the number of active online bank sessions never really recovers from the mid-afternoon dip but online bank use rather continues at practically same level until it starts to decline more rapidly early in the evening as the weekend is about to being. On Mondays there is a clear morning peak followed by a mid-afternoon dip. The number of online bank sessions does not, however, increase after the dip. We can only conjecture that a sizeable portion of people have taken care of their finances for the day during the Monday morning peak, which is consistently the most active period of online bank use of the whole week.

\section{Conclusions}

The number of active online bank sessions follows the daily and weekly cyclic patterns prescribed by the self-control theory. Neither daily nor weekly variation in online bank use follows the rhythm one would expect to see considering that our data depicts use of a service offered to consumers. The majority of online bank users work on weekdays yet we find that people schedule their online bank use to prime office hours. This pattern of use can't be explained away by any trivial explanation, for example that people would have had Internet access only on the workplace. The share of households with Internet connectivity closely followed the share of population using online bank.

That we observe a substantial difference in the average number of active online bank sessions between weekdays and the days of the weekend would be equally surprising and difficult to explain in absence of the self-control theory. True, people probably time many social events on weekends, but it is difficult to see how even this could cause the dramatic difference in online bank activity we see between weekdays and the weekend. The whole week's low, 137131 active sessions on Saturdays, is little more than half of the 238265 average sessions on Fridays, Friday being quietest of the weekdays. Considering that our data come from an online bank offered to consumers, we would expect to see more active use during the weekend if motivation to use the service were the only mechanism controlling consumers' actions.

Finally, the rather dramatic decrease in online bank activity from Monday to Friday is probably the clearest indicator for the influence of (lack of) selfcontrol on online bank use. Even if daily variation in online bank use were dismissed as resulting from people organizing their daily routines around some activities that would have forced them to time their use of online bank in the mornings, it is difficult to see how similar logic could be applied to explain the weekly rhythm in online bank use. In particular, the weekdays from Monday to Thursday are usually organized quite similarly, yet we see a substantial decrease in the number of active online bank sessions from Monday to Thursday.

In sum, we conclude that our data demonstrates that use of utilitarian IT, such as online bank services, depends on the self-control mechanism and those limited resources that the mechanism consumes. Further, self-control theory tells us that intrinsically rewarding activities such as hedonic use of IT do not depend on the self-control resources. Thus, different sets of mental mechanisms determine utilitarian and hedonic use of IT. 


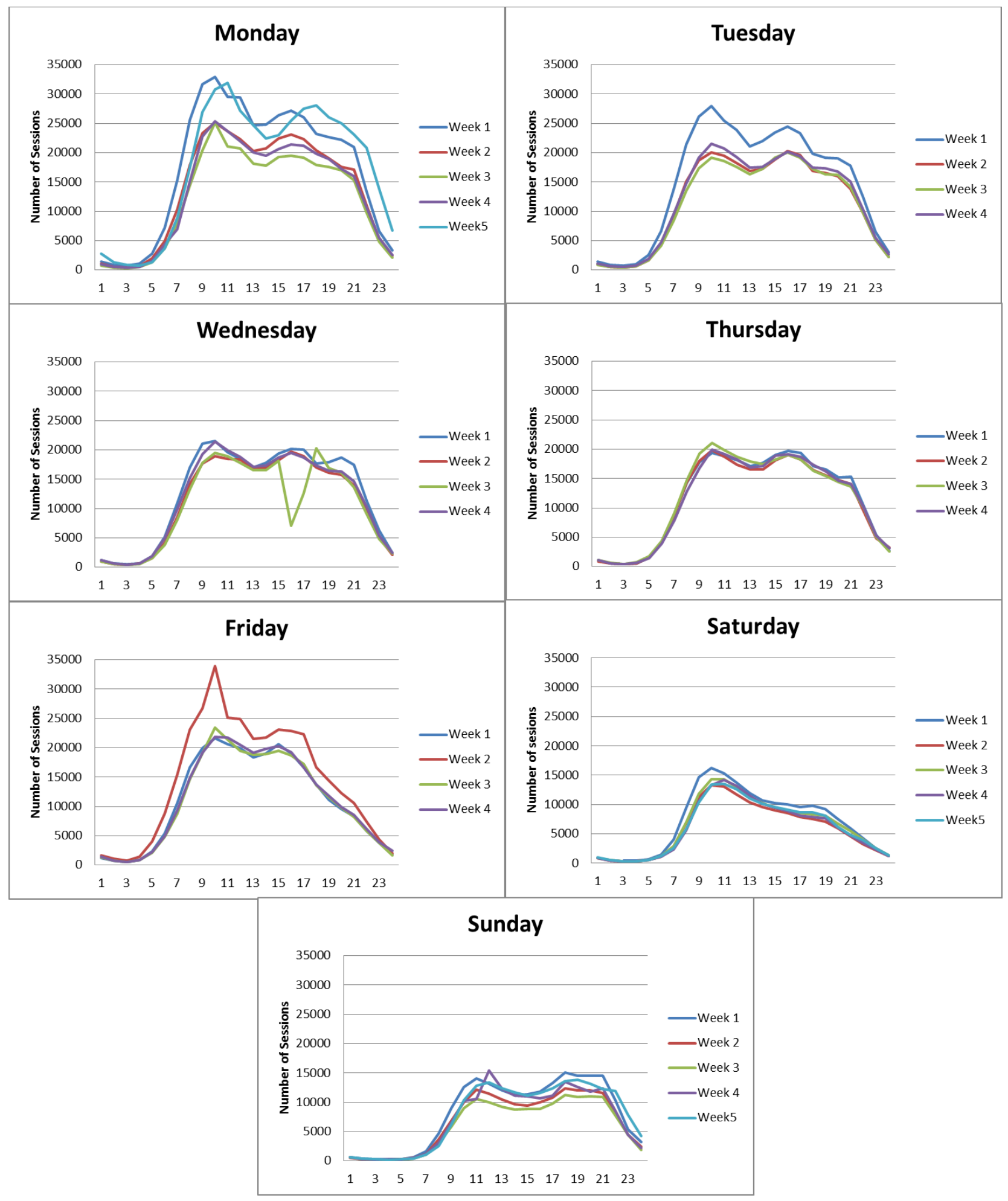

Figure 1: Distribution of active online bank sessions over the week. 
Table 1: Regression models fitted to active online bank sessions on weekdays.

\begin{tabular}{|c|c|c|c|c|c|c|c|c|}
\hline \multirow[b]{2}{*}{$\begin{array}{c}\text { Day of the } \\
\text { week }\end{array}$} & \multicolumn{5}{|c|}{ Variables in Equation } & \multicolumn{2}{|c|}{ Analysis of Variance } & \multirow[b]{2}{*}{$R$ Square } \\
\hline & Variables & Beta & $\begin{array}{l}\text { Std. } \\
\text { Err. }\end{array}$ & $t$ value & $p$ value & $F$ ratio & p value & \\
\hline \multirow[t]{2}{*}{ Monday } & Intercept & 0.068 & 0.076 & 0.853 & 0.414 & 43.636 & $<0.001$ & 0.814 \\
\hline & Time of day & -0.814 & 0.123 & -6.606 & $<0.001$ & & & \\
\hline \multirow[t]{2}{*}{ Tuesday } & Intercept & 0.051 & 0.136 & 0.375 & 0.715 & 8.438 & 0.016 & 0.458 \\
\hline & Time of day & -0.610 & 0.210 & -2.905 & 0.016 & & & \\
\hline \multirow[t]{2}{*}{ Wednesday } & Intercept & 0.136 & 0.091 & 1.486 & 0.168 & 19.670 & 0.001 & 0.663 \\
\hline & Time of day & -0.627 & 0.141 & -4.435 & 0.001 & & & \\
\hline \multirow[t]{2}{*}{ Thursday } & Intercept & -0.034 & 0.100 & -0.338 & 0.742 & 14.583 & 0.003 & 0.593 \\
\hline & Time of day & -0.593 & 0.155 & -3.819 & 0.003 & & & \\
\hline \multirow[t]{2}{*}{ Friday } & Intercept & -0.102 & 0.076 & -1.342 & 0.209 & 44.083 & $<0.001$ & 0.815 \\
\hline & Time of day & -0.780 & 0.117 & -6.640 & $<0.001$ & & & \\
\hline
\end{tabular}

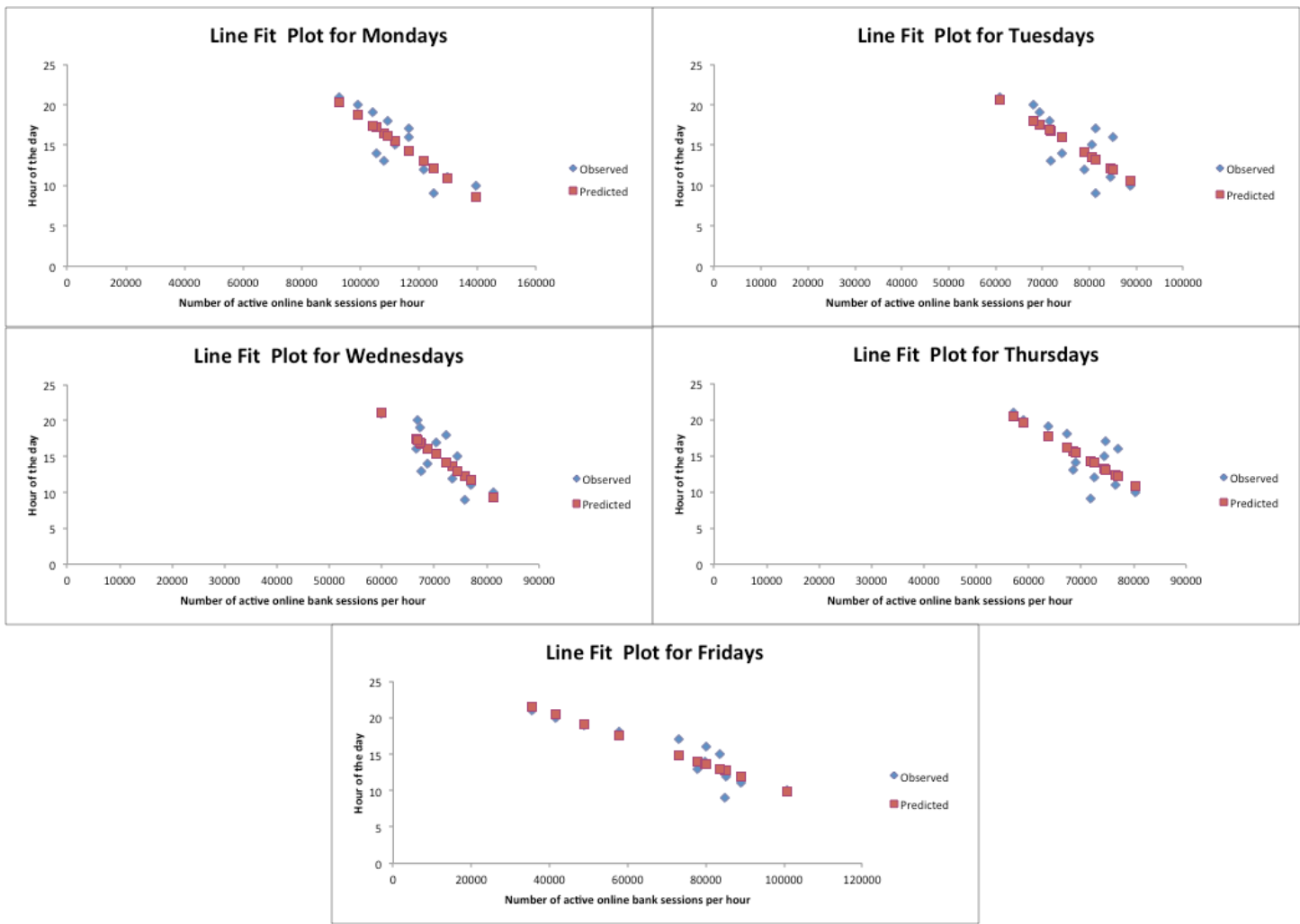

Figure 2: Fitted regression curves on active online bank sessions from on weekdays. 
Table 2: Weekday by weekend comparison of number of active online bank sessions.

Pane 1: Weekday by Weekend comparison of active online bank sessions.

\begin{tabular}{lcccccc}
\hline & & & \multicolumn{4}{c}{ Compared to } \\
\cline { 2 - 7 } & \multicolumn{2}{c}{ Number of active sessions } & \multicolumn{2}{c}{ Saturday } & \multicolumn{2}{c}{ Sunday } \\
\cline { 2 - 7 } & Average & Variance & z value & $\mathrm{p}$ value & z value & $\mathrm{p}$ value \\
Monday & 329536 & 2350478488 & 25.83 & $<0.001$ & 23.95 & $<0.001$ \\
Tuesday & 274729 & 1793093142 & 20.83 & $<0.001$ & 18.75 & $<0.001$ \\
Wednesday & 256622 & 958809576 & 23.49 & $<0.001$ & 20.62 & $<0.001$ \\
Thursday & 244100 & 1291364945 & 18.47 & $<0.001$ & 16.10 & $<0.001$ \\
Friday & 238265 & 2319818400 & 13.52 & $<0.001$ & 11.81 & $<0.001$ \\
Saturday & 137131 & 257727425 & & & & \\
Sunday & 148822 & 326317800 & & & & \\
& & & & & & \\
\end{tabular}

Pane 2: Weekday by weekday comparison of active online bank sessions.

\begin{tabular}{|c|c|c|c|c|c|c|c|c|}
\hline & \multicolumn{2}{|c|}{ Mon } & \multicolumn{2}{|c|}{ Tue } & \multicolumn{2}{|c|}{ Wed } & \multicolumn{2}{|c|}{ Thu } \\
\hline & $z$ value & $p$ value & $z$ value & $p$ value & $z$ value & $p$ value & $z$ value & $p$ value \\
\hline Tue & 5.837 & $<0.001$ & & & & & & \\
\hline Wed & 8.689 & $<0.001$ & 2.366 & 0.009 & & & & \\
\hline Thu & 9.669 & $<0.001$ & 3.764 & $<0.001$ & 1.799 & 0.036 & & \\
\hline Fri & 9.107 & $<0.001$ & 3.874 & $<0.001$ & 2.181 & 0.015 & 0.659 & 0.255 \\
\hline
\end{tabular}

Table 3: Mid-afternoon 'dip' in active online bank sessions.

\begin{tabular}{|c|c|c|c|c|c|c|c|}
\hline & \multirow[b]{2}{*}{$\begin{array}{c}\text { Morning } \\
\text { high }\end{array}$} & \multirow[b]{2}{*}{$\begin{array}{l}\text { Afternoon } \\
\text { 'dip' }\end{array}$} & \multirow[b]{2}{*}{$\begin{array}{c}\text { Afternoon } \\
\text { high }\end{array}$} & \multicolumn{2}{|c|}{$\begin{array}{l}\text { Morning highest - } \\
\text { afternoon lowest }\end{array}$} & \multicolumn{2}{|c|}{$\begin{array}{l}\text { Afternoon lowest - } \\
\text { afternoon highest }\end{array}$} \\
\hline & & & & $\mathrm{z}$ value & $\mathrm{p}$ value & $\mathrm{z}$ value & $\mathrm{p}$ value \\
\hline Mon & 27868 & 21059 & 23335 & 3.304 & $<0.001$ & 1.236 & 0.108 \\
\hline Tue & 22176 & 17945 & 21237 & 1.869 & 0.031 & 2.181 & 0.015 \\
\hline Wed & 20307 & 16901 & 19793 & 5.087 & $<0.001$ & 11.938 & $<0.001$ \\
\hline Thu & 20086 & 17132 & 19238 & 6.360 & $<0.001$ & 6.353 & $<0.001$ \\
\hline Fri & 25212 & 19475 & 20015 & 1.906 & 0.028 & 0.083 & 0.467 \\
\hline
\end{tabular}

\section{Discussion}

In this paper, we find that the rhythm of utilitarian IT use conforms to the cyclic availability of self-control resources. In our data we see that once free from the constraints of the conventional services production schedule, online bank use largely adjusts to the daily and weekly cyclic patterns that characterize consumption and replenishment of the self-control resources.

The day rhythm in use of utilitarian IT closely follows the regular pattern of self-control resources: As is the case with most diurnal processes that influence man's life, capacity for self-control rises rather rapidly in the morning, declines toward mid-afternoon, and rises again late in the afternoon only to decline rapidly at nightfall. This means that man is more likely able to inhibit distractions and resist temptations in the morning and late afternoon, and less so in midafternoon and the evening. As utilitarian IT use is somewhat taxing, it depends on available self-control resources and therefore utilitarian IT use peaks in the morning. As utilitarian IT use also depletes the limited self-control resources, it is actually self-defeating in the sense that every utilitarian use episode complicates the subsequent similar episodes during the rest of the day. 
The weekly rhythm of utilitarian IT use too follows the cyclic availability of self-control resources throughout the period of the week. We observe steady weekly pattern in the active online bank sessions. Use of online bank peaks in the beginning of the week and declines toward the end of the week. What is most striking is that the frequency distribution of active online bank sessions remains remarkably similar for each day of the week from week to week. The week rhythm is probably the most enlightening example of utilitarian IT use being subject to a limited resource, i.e. that needed for self-control. The week as a time unit is not based on the movement of celestial bodies, which could entrain the cyclic biological processes of the human body. Rather, the week is a purely artificial creation [18, 11]. Hence, there is no compelling biological rhythm, which in itself would force people to schedule their work and rest over the week and produce any identifiable pattern in utilitarian IT use. Rather, the weekly cycle of online bank use, which we observe in our data, demonstrates that utilitarian IT use is very much part of the modern man's pattern of everyday life: We overspend some of our mental resources on weekdays, and have to replenish the resources on a regular basis. The week is a cultural creation designed to allow for just such replenishment [19].

Taken together, our findings suggest that consumption of utilitarian IT, such as online bank services, depends on self-control resources, which are in limited supply and need to be replenished on a regular basis, and that daily periods of rest do not entirely suffice for such replenishment. The weekend is oriented toward leisure, and extended availability of bank services afforded by ubiquitous information technology has not dramatically changed that situation: While online bank services are better than conventional services in conforming more closely to the natural daily demand schedule, they do not appreciably change the demand schedule and, hence, the 24/7 supply of online bank services satisfies marginal demand unless the service is offered globally, over the time zones. Our findings help explain why earlier studies have reported rather disappointing results when consumers have been asked to evaluate the benefits of a constant 24/7 supply of utilitarian IT: Human biology prevents dramatic changes in demand schedules for such services.

The most important practical message of our study is that people who design or market technology based services should closely pay attention to the context and timing of contacting their potential customers. Our observations suggest that morning is the best time to expose consumers to information, such as reminders for use, about utilitarian services, which are used because they help people achieve some higher-level goals rather than because of using them were intrinsically rewarding. Similarly, early weekdays are better suited for exposing consumers to information about the service. When technology use is not in itself rewarding, there is a declining tendency to use the technology over the day and the week. Weekends are needed and used for replenishment of self-control resources, and it is difficult to see how any reasonable effort could encourage people to significantly increase their use of utilitarian IT on weekends.

Learning to understand the multifaceted daily lives of consumers is becoming a competitive necessity: The success of businesses will be increasingly based on their ability to find spaces (and times) of market potential in people's daily lives. More research is needed, though, to encourage this development. The combined effects of economic, physiological and cultural rhythms have only rarely been studied simultaneously, because the practice has been to approach natural and cultural phenomena from the perspective of isolated sciences and isolated phenomena. What is essential is to place emphasis on the origin of rhythms as an emergent network property. The entire pulse of a society is born as a result of interactions between the biological rhythms of individuals on the one hand, and social and economic rhythms on the other. Rhythms are literally embodied in us. Rhythms are embedded in social and technical systems, and are enacted more or less purposefully by various interdependent agents.

In an optimistic view, firms will learn to exploit new diagnostics and extensive customer databases to increasingly better adapt to the diverse daily rhythms of consumers [20]. Businesses will start to compete over a place in the daily lives of consumers by, for example, enriching their supply to serve the needs of ever smaller consumer segments and creating "portion sizes" for services that suit consumers' time use better. In a critical view, the better ability of businesses to control how consumers use their time and money through extensive databases could lead to a decline in the power of consumers [21]. The companies that own the prime of consumers' time are on the path to success. This is exactly why it pays off to dig into the repositories of digital consumption data that constantly accumulate in many businesses, but lie dormant because too few individuals realize the real value of the data.

The methodological contribution of our study lies in demonstrating how data, automatically collected by the servers producing digital services, can be used to meaningfully study consumption rhythms. Conventionally, consumer studies have investigated solitary consumer events, because there has been little 
available data to investigate consumption rhythms. The ability of the information systems field to offer analytical techniques for life rhythm analyses enables IS researchers to contribute to other fields of social science. In rhythm-based businesses, market research is increasingly shifting its attention towards the timespace relationships of consumer activities. The duration and amount of production, distribution and consumption of services (e.g. daily practices connected with eating) and their potential overlapping and mutual connections in time and space can today be diagnosed more and more effectively. Thanks to the Internet, seemingly distinct activities can be brought together, and those operators who have long been close to their customers can develop crucially novel integrations of daily practices to enhance their electronic business, for example.

The main theoretical contribution of our paper is that we connect distinct behavioral patterns to use of utilitarian and hedonic IT, the two types of information technologies, which IS researchers have thus far differentiated only by the different belief sets, i.e. usefulness vs. fun, driving technology use. The important theoretical demarcation in our explanation for patterns of IT use is that the self-control mechanism influences utilitarian IT use but not hedonic IT use. It would be quite difficult if not impossible to explain the observed daily and weekly cyclic patterns in utilitarian IT use by motivation. At least the standard measures for motivation, such as beliefs, attitudes, and intentions, which are commonly used to measure motivation, would struggle to account for these patterns. Moreover, as self-control is a mechanism that operates independent of one's motivation to use IT, self-control mechanism offers one plausible explanation for the ever more ubiquitous gap observed between motivation to use IT and actual IT use (e.g. $[22,23])$.

As a deeper level contribution, our findings may help IS researchers to better conceptualize information technology's role as a component of the information system, particularly by strengthening our understanding of the human-IT relationship. Although this relationship is one of the foci of IS research, the role that technology plays in this relationship remains vague. We are much more knowledgeable about why people accept and use technology than we are about how technology's characteristics influence its use patterns. A number of scholars have lamented over the years that the information technology is largely absent from IS theory (e.g. [24]). We think that there is little space for such theorizing for as long as it continues to be impossible to theoretically identify different types of technologies based on the role the technology plays in the human-IT relationship. In that respect, deeper understanding in the difference between utilitarian and hedonic IT can become a useful starting point for more meaningful conceptualizing of IT. That use of utilitarian IT and hedonic IT should follow different patterns, because they depend on different mental mechanisms and resources, points to explanations of IT use, which acknowledge that use is contingent to the type of technology. IS, as a discipline, would benefit from promoting such technology based contingencies, as that would strengthen our claim that systems thinking is the approach to study the relationships between man, information, and technology.

\section{References}

[1] H. van der Heijden,"User acceptance of hedonic information systems," MIS Quarterly 28(4), 2004, pp. 695-704.

[2] A. Öörni, and K. Lyytinen, "Looking Past Planned and Habitual IT Use", 48 ${ }^{\text {th }}$ Hawaii International Conference on System Sciences. Kauai, January 5-8, 2015.

[3] K. D. Vohs, R. F. Baumeister, B. J. Schmeichel, J. M. Twenge, N. M. Nelson, and D. M. Tice, "Making choices impairs subsequent self-control: a limitedresource account of decision making, f-regulation, and active initiative", Journal of Personality and Social Psychology 94(5), 2008, pp. 883-98.

[4] J. Laran, and C. Janiszewski, "Work or Fun? How Task Construal and Completion Influence Regulatory Behavior", The Journal of Consumer Research 37(6), 2011, pp. 967-983.

[5] R. F. Baumeister, E. Bratslavsky, M. Muraven, and D. M. Tice, "Ego depletion: Is the active self a limited resource?" Journal of Personality and Social Psychology 74, 1998, pp. 1252-1265.

[6] M. S. Hagger, C. Wood, C. Stiff, and N. L. Chatzisarantis. "Ego depletion and the strength model of self control: A meta-analysis", Psychological Bulletin 136(4), 2010, pp. 495-525.

[7] A. Diamond, "Executive functions", Annu Rev Psychol 64, 2013, pp. 135-168.

[8] R. Custers, and H. Aarts, "The Unconscious Will: How the Pursuit of Goals Operates Outside of Conscious Awareness", Science 329, 2010, pp. 47-50. 
[9] A. Dijksterhuis, and H. Aarts, "Goals, Attention, and (Un)Consciousness", Annual Review of Psychology 61, 2010, pp. 467-490.

[10] P. Steel, "The Nature of Procrastination: A MetaAnalytic and Theoretical Review of Quintessential Self-Regulatory Failure", Psychological Bulletin 133(1), 2007, pp. 65-94.

[12] G. Aston-Jones, and J. D. Cohen, "An Integrative Theory of Locus Coeruleus-Norepinephrine Function: Adaptive Gain and Optimal Performance", Annual Review of Neuroscience 28, 2002, pp. 403-450.

[11] J. S. Eccles, and A. Wigfield, "Motivational beliefs, values, and goals", Annual Review of Psychology 53, 2002, pp. 109-132.

[13] W. Hofmann, R. F. Baumeister, G. Forster, and K. D. Vohs, "Everyday temptations: An experience sampling study on desire, conflict, and self-control", Journal of Personality and Social Psychology 102(6), 2012, pp. 1318-1335.

[14] W. Hofmann, K. D. Vohs, K.D., and R. F. Baumeister, "What people desire, feel conflicted about, and try to resist in everyday life", Psychological Science 23(6), 2012, pp. 582-588.

[15] J. Levav, H. Heitmann, A. Herrmann, and S.S. Iyengar, "Order in product customization decisions: Evidence from field experiments", The Journal of Political Economy 118(2), 2010, pp. 274-299.

[16] C. J. Beedie, and A. M. Lane, "The role of glucose in self-control: another look at the evidence and an alternative conceptualization", Personality and Social Psychology Review 16(2), 2012, pp. 143-53.
[17] M. Hagger, and N. L. Chatzisarantis, "The sweet taste of success: The presence of glucose in the oral cavity moderates the depletion of self-control resources" Personality and Social Psychology Bulletin 39(1), 2013, pp. 28-42.

[18] E. Zerubavel, "The standardization of time: a sociohistorical perspective", The American Journal of Sociology 88(1), 1988, pp. 1-23.

[19] E. Zerubavel, The Seven Day Circle: The History and Meaning of the Week, University Of Chicago Press, 1989.

[20] C.K. Prahalad, and V. Ramaswamy, "Co-creating unique value with customers", Strategy \& Leadership 32(3), 2004, pp. 4-9.

[21] D. Zwick, and J. D. Knott, "Manufacturing Customers; The database as new means of production", Journal of Consumer Culture 9(2), 2009, pp. 221-247.

[22] V. Venkatesh, M. G. Morris, and P. L. Ackerman, "A Longitudinal Field Investigation of Gender Differences in Individual Technology Adoption Decision-Making Processes", Organizational Behavior and Human Decision Processes 83(1), 2000, pp. 33-60.

[23] F. D. Davis, and V. Venkatesh, "Toward prototype user acceptance testing of new information systems: Implications for software project management", IEEE Trans. Engrg. Management 51(1), 2004, pp. 31-46.

[24] W. J. Orlikowski, and C. S. Iacono, "Desperately Seeking the 'IT' in IT Research - A Call to Theorizing the IT Artifact", Information Systems Research12(2), pp. 121-134. 